\title{
Seed size and adventitious (nodal) roots as factors influencing the tolerance of wheat to waterlogging
}

\author{
D. K. Singh $h^{\mathrm{A}, \mathrm{B}, \mathrm{D}}$ and $V$. Sing $h^{\mathrm{A}, \mathrm{C}}$ \\ A Pastoral and Veterinary Institute, Department of Primary Industries, Hamilton, Vic. 3300, Australia. \\ ${ }^{B}$ Farming Systems, Agency for Food and Fibre Sciences, DPI/APSRU, Roma, Qld 4455, Australia. \\ ${ }^{\mathrm{C}}$ Department of Botany, La Trobe University, Bundoora, Vic. 3086, Australia. \\ ${ }^{\mathrm{D}}$ Corresponding author; email: Dhananjay.Singh@dpi.qld.gov.au
}

\begin{abstract}
In a glasshouse study, two experiments were conducted to understand how inherent variability, such as the seed size or mass, and formation of adventitious nodal roots might influence the tolerance of various wheat and triticale cultivars at different growth stages to waterlogging. Waterlogging at germination resulted in $11 \%$ seedling mortality, but the waterlogged seedlings had a $19 \%$ increase in shoot mass per plant, with no difference in root mass compared with non-waterlogged seedlings. Waterlogging at the 3-leaf stage was deleterious to only a few cultivars. On average, larger seed resulted in greater plant growth for most of the cultivars, and seed mass was positively related to the plant biomass and adventitious nodal root mass under waterlogged conditions. A decreasing oxygen concentration with increasing duration of waterlogging and soil depth did not affect the plant growth and visual stress symptoms, chlorosis, until the oxygen concentration decreased to less than $10 \%$ in the bottom depths. The highest yielding triticale cultivar, Muir, and wheat cultivars Brookton and Frame had the greatest seed mass, plant biomass, and relative growth rates under waterlogged conditions, compared with the lowest yielding wheat cultivars, Amery, Silverstar, and More. However, the degree of 'waterlogging tolerance', expressed as the percent ratio of plant biomass or growth rates under waterlogged conditions relative to the non-waterlogged control conditions, appeared to be greatest for the low-yielding cultivars, indicating a 'cautious approach' when screening tolerant cultivars.
\end{abstract}

Additional keywords: adventitious nodal roots, cultivar, seed, waterlogging tolerance.

\section{Introduction}

Soil waterlogging during autumn and winter is a major environmental constraint to survival, early seedling vigour, vegetative growth, and grain yield of wheat cultivars in the high rainfall zone $(>500 \mathrm{~mm}$ annual rainfall $)$ of south-western Victoria (McDonald and Gardner 1987; Stephens and Lyons 1998). Vegetative growth and grain yield of sensitive species are generally decreased under waterlogged conditions due to the lack of sufficient oxygen in the rooting zone (Kozlowski 1984; Drew 1992). The availability of oxygen under hypoxia/anoxia results in decreased metabolism in root tissues, reduced size of the root system, and decreased efficiency of water and nutrient uptake by roots, leading to chlorosis, senescence, stunted growth and death of various plant parts, and reduced grain yield (Trought and Drew 1980a, 1980b; Belford 1981; Drew et al. 1994; Huang et al. 1994).

The roots are highly sensitive to hypoxia, but preferential allocation of photosynthates can occur under waterlogged conditions, to develop adventitious roots in tolerant species
(Bacanamwo and Purcell 1999). The formation of adventitious roots is a morphological phenomenon commonly associated with species tolerant to waterlogging and serves as a mechanism for replacing either dead primary roots or those whose function is impaired by hypoxia/anoxia at depth (Huang et al. 1994, 1997; Lin 2000). In cereals, the nodal root systems may develop aerenchyma (interconnecting gas channels), which allow the diffusion of oxygen from shoots to waterlogged roots, thus improving the tolerance of plants to waterlogging (Armstrong 1979; Justin and Armstrong 1987; He et al. 1996; Lin 2000).

Plant sensitivity to waterlogging can change with aging of plants, and seed size and seed mass. Cannell et al. (1980) and Meyer and Barrs (1988) reported a decreased sensitivity to waterlogging with age of the wheat plants. Similarly, Setter (2000) reported that the seed mass accounted for up to $27 \%$ of the variation in survival of seeds subjected to waterlogging for various crops. However, the relationships between seed mass and tolerance of seedlings at various growth stages to waterlogging have not been studied. Larger effects of seed 
mass on early vigour and seedling growth have been reported for various Australian and overseas cultivars of wheat grown in non-waterlogged conditions (Rebetzke and Richards 1999; Richards and Lukacs 2002). In particular, Richards and Lukacs (2002) found close linear relationships between seed mass and seedling growth in several studies over various wheat cultivars, but under non-waterlogged control conditions. The effect of seed mass on growth might be translated to plants, when subjected to waterlogging.

There is also little information on the variations in tolerance of Australian wheat cultivars to waterlogging, particularly in the temperate high rainfall zone of south-western Victoria. In this study, 2 glasshouse experiments were conducted to understand criteria for screening tolerant Australian cultivars, and how inherent variability, such as the seed size and seed mass, and formation of adventitious nodal roots might influence the magnitude of tolerance to waterlogging at different growth stages. In the first experiment, waterlogging was imposed just after the germination of various wheat cultivars, whereas in the second experiment, waterlogging was imposed at the 3-leaf stage, just before the start of tillering, on wheat and triticale cultivars.

\section{Materials and methods}

Experiment 1

\section{Plant material and treatments}

Eighteen wheat cultivars (Amery, Brennan, Brookton, Carnamah, Chara, Declic, Dollarbird, Frame, Goldmark, Goroke, Kellalac, Mira, More, Patterson, Rosella, Silverstar, Spear, and Tennant) were selected from the germplasm collection at the Victorian Institute for Dryland Agriculture (VIDA), Horsham, Vic.

Treatments were arranged in a split-split plot design and consisted of factorial combinations of 18 cultivars $\times 2$ seed sizes (large and small) $\times 2$ regimes of soil water (waterlogged and non-waterlogged control). The soil water regimes were established as the main plots, seed size as the subplots, and cultivars as the sub-subplots. There were 4 replications (Blocks). Subplot treatments (large and small seeds in seedling trays) within a block were re-randomised weekly.

\section{Growing conditions and measurements}

Seeds of each cultivar were separated into small $(1.75-2.50 \mathrm{~mm}$ diam.) and large (2.75-3.25 mm diam.) size by using different sizes of sieves, and seed mass for 1000 seeds was determined for each size by counting 3 lots of seed. Seed mass (1000 seeds) for large and small seed ranged from 36.4 to $51.9 \mathrm{~g}$ and 27.2 to $36.4 \mathrm{~g}$, respectively. Small and large size seeds of each cultivar were then germinated in Petri dishes. Fifteen germinated seeds per treatment were then transplanted into seedling trays containing 1:1 soil-potting mix medium. Three days after transplanting, a waterlogging treatment was imposed by flooding the seedling trays, placed in a specially designed large container, to the top of the soil with stored rainwater. The rainwater had a dissolved oxygen concentration of 30-50\%, which was determined later, using a hand-held oxygen meter (Sension 156 Portable Multipara meter, $\mathrm{HACH}$ Co., CO, USA). Each morning and evening, the water level in the flooded container was topped up to above the soil surface, whereas the control treatment was watered, just enough to keep the soil moist, but not saturated.
Development of leaf chlorosis, adventitious nodal roots for waterlogged plants, leaf number, and number of senescent leaves were assessed visually on a daily basis, after transplanting. Four weeks after imposed waterlogging, surviving seedlings were counted and removed from the soil. Green leaves, senescent or wilted leaves, stem, and roots were separated and counted. Dry weight of each plant part was determined after $48 \mathrm{~h}$ at $70^{\circ} \mathrm{C}$. Survival of seedlings was estimated as the per cent ratio of surviving seedlings to the 15 originally transplanted seedlings, and the root to shoot ratio was calculated on a dry-weight basis.

\section{Statistical analysis}

Analysis of variance for a split-plot design, using GENSTAT 5.3 software, was performed to determine the significance of main effects and their interaction for various parameters. Linear regressions were used to describe relationships between seed mass and root and shoot mass.

\section{Experiment 2}

\section{Experimental design and treatments}

This experiment consisted of a factorial combination of 2 regimes of soil water (waterlogged and non-waterlogged control), 3 harvests, and 9 cultivars ( 8 wheat, and 1 triticale) in a split-split-plot design with 4 replications. The 3 harvests were arranged as the main plots, soil water regimes as the subplots, and cultivars as the sub-subplots. Six spring and 2 winter wheat cultivars were selected from the Expt 1; these cultivars included low and high yielding, and early to late maturing lines, and were compared against one triticale line, Muir.

\section{Growing conditions}

Large seeds $(2.75-3.25 \mathrm{~mm})$ of each cultivar were planted in PVC pots ( $100 \mathrm{~cm}$ long, $8.5 \mathrm{~cm}$ in diam.), containing sterilised fine sand. The experimental pots had closed bottom ends, and were fitted with 2 drain tubes. Three days before planting of seeds, $100 \mathrm{mg}$ Aquasol, dissolved in $1 \mathrm{~L}$ of water, was applied to each pot, to provide essential mineral nutrients. Seedlings were thinned to 1 per pot after 2 weeks of planting, and allowed to grow for a further 1 week. Drain tubes at the bottom of the pots were kept closed during the total 3 weeks of germination and establishment of plants. Thereafter, the drain tubes of each pot were opened for $\sim 4 \mathrm{~h}$ to drain out the soil water containing nutrient solution. After draining, the drain tubes were closed for pots assigned to the waterlogged treatment, whereas tubes were kept open for the pots assigned to the non-waterlogged, free-draining control treatment. This provided similar nutritional conditions for initial development of the plants. Otherwise, fertilisation in waterlogged pots with closed drain tubes, and in non-waterlogged, free-draining control pots, with open drain tubes, would have resulted in different concentrations of nutrient solution. This was realised in preliminary experiments.

Waterlogging was imposed by flooding 2 sets of pots with stored rainwater to $3-5 \mathrm{~cm}$ above the surface of the soil for 3 weeks. The water level in the waterlogged pots was topped up after 1 week, whereas the non-waterlogged control plants were watered with a similar amount of water every 3-4 days. At the end of the waterlogging period, one set of waterlogged plants was harvested, whereas the drain tubes in the other set were opened to drain the excess water, and plants were left to recover for 3 weeks. Plants were destructively harvested for measurements: (1) before the imposed waterlogging at around the 3-leaf stage (Harvest 1), (2) after 3-week waterlogging period between the 3- and 5-leaf stage (Harvest 2), and (3) after the 3-week recovery period between 5- and 7-leaf stage (Harvest 3 ). 


\section{Measurements}

The concentrations (\%) of dissolved oxygen in water were measured at the end of the second and third week of imposed waterlogging. Water was sampled from 3 depths: (1) standing water above the soil surface, (2) at $5 \mathrm{~cm}$ depth, and (3) below $10 \mathrm{~cm}$ depth, by inserting tubing, and using a $40-\mathrm{mL}$ Hamilton syringe. The sampled water from each depth was collected into a $25-\mathrm{mL}$ glass bottle. The oxygen concentration was determined immediately from each depth using a hand-held oxygen meter (Sension 156 Portable Multipara meter).

The plant biomass at each harvest included cumulative dry mass of leaves, main stem, tillers, seminal, and nodal roots. Intact plants were taken out from the pots and soil around the roots was washed under running tap water. Plant parts were separated and dried at $70^{\circ} \mathrm{C}$ for $48 \mathrm{~h}$ at the end of each harvest.

The relative growth rate (RGR) was determined for the plant biomass under waterlogged (WL) and control (C) conditions over time between Harvest 1 and 2:

$\operatorname{RGR}(\mathrm{C})=[\operatorname{Biomass}(\mathrm{C})$ at Harvest $2-$ Biomass $(\mathrm{C})$ at Harvest 1] $(\mathrm{t} 2-\mathrm{t} 1)$

$\operatorname{RGR}(\mathrm{WL})=[$ Biomass $(\mathrm{WL})$ at Harvest $2-$ Biomass $(\mathrm{C})$ at Harvest 1]/ $(\mathrm{t} 2-\mathrm{t} 1)$

The degree of 'waterlogging tolerance' for each cultivar was calculated as the percentage of plant biomass or RGR under waterlogged, relative to non-waterlogged, control conditions. There was no need for data transformation as the data were normally distributed for each parameter presented in this study.

\section{Results}

\section{Experiment 1}

\section{Seed size and seed mass}

Differences among cultivars for seed size and 1000-seed mass were highly significant $(P<0.001)$. Larger seed ranged from 2.75 to $3.25 \mathrm{~mm}$, and small seed from 1.75 to $2.5 \mathrm{~mm}$ in diameter. Seed mass (1000 seeds) for large and small seed ranged from 36.4 to $51.9 \mathrm{~g}$ and 27.2 to $36.4 \mathrm{~g}$, respectively. The cultivars with the heaviest seed (Brookton and Frame) had a $30 \%$ greater mass of seed compared with those with the lightest seed, Amery, Spear, and Silverstar (Table 1).

\section{Effect of seed size on seedling growth}

Visual assessment, during germination, indicated that the development of radicle and coleoptile was highly variable, and was dependent on the seed size, for most cultivars. Generally, larger seed, across cultivars, exhibited greater radicle and coleoptile development compared with smaller seed (data not presented).

Brookton and Frame were the largest producers of seedling biomass with larger or smaller seed, whereas Amery, Silverstar, and More had the lowest seedling biomass for both seed sizes (Table 1). There was a highly significant $(P<0.001)$ interaction between seed sizes and cultivars for the seedling biomass, over non-waterlogged control (C) and waterlogged (WL) conditions. All cultivars had increased seedling biomass with the larger seed relative to the smaller seed, except Tennant, which showed the opposite effects. On average, across cultivars and soil water regimes, the larger
Table 1. Interaction effects between large and small seed sizes on seed mass ( $\mathrm{g} / 1000$ seeds), and seedling biomass ( $\mathrm{g}$ ) across waterlogged and non-waterlogged control plants, for 18 cultivars in Expt 1

\begin{tabular}{|c|c|c|c|c|}
\hline \multirow[t]{2}{*}{ Cultivars } & \multicolumn{2}{|c|}{ Seed mass } & \multicolumn{2}{|c|}{ Seedling biomass } \\
\hline & Large & Small & Large & Small \\
\hline \multicolumn{5}{|c|}{ Spring wheat } \\
\hline Brookton & 51.9 & 36.4 & 0.22 & 0.19 \\
\hline Frame & 50.0 & 35.3 & 0.17 & 0.14 \\
\hline Dollarbird & 49.0 & 29.8 & 0.15 & 0.10 \\
\hline Carnamah & 47.0 & 29.8 & 0.14 & 0.11 \\
\hline Rosella & 46.6 & 34.4 & 0.16 & 0.14 \\
\hline Goldmark & 44.7 & 35.7 & 0.14 & 0.12 \\
\hline Patterson & 44.5 & 28.3 & 0.14 & 0.11 \\
\hline Declic & 44.1 & 29.2 & 0.15 & 0.12 \\
\hline Mira & 43.8 & 31.1 & 0.16 & 0.11 \\
\hline Chara & 43.8 & 29.2 & 0.15 & 0.12 \\
\hline Goroke & 42.5 & 26.9 & 0.16 & 0.10 \\
\hline Brennan & 41.6 & 28.2 & 0.15 & 0.11 \\
\hline Kellalac & 40.7 & 25.7 & 0.15 & 0.11 \\
\hline Amery & 39.4 & 23.5 & 0.12 & 0.09 \\
\hline Silverstar & 39.0 & 23.6 & 0.13 & 0.08 \\
\hline Spear & 36.4 & 27.2 & 0.14 & 0.12 \\
\hline \multicolumn{5}{|c|}{ Winter wheat } \\
\hline Tennant & 46.6 & 29.9 & 0.14 & 0.18 \\
\hline More & 41.0 & 27.8 & 0.11 & 0.08 \\
\hline Significance & \multicolumn{2}{|c|}{$* * *$} & \multicolumn{2}{|c|}{$* * *$} \\
\hline 1.s.d. $(P=0.05)$ & \multicolumn{2}{|c|}{2.09} & \multicolumn{2}{|c|}{0.027} \\
\hline
\end{tabular}

$* * * P<0.001$.

seed had a $26 \%$ greater biomass $(P<0.001)$ compared with the smaller seed (Table 1).

\section{Effect of waterlogging}

The survival of germinated seed under waterlogged conditions was $11 \%$ less $(P<0.05)$ than for the control, but shoot dry mass of surviving seedlings increased under waterlogged conditions by $19 \%(P<0.001)$, with no difference in the root mass of plants between waterlogged and control treatments (Table 2).

At the end of the experiment, there was a trend for the waterlogged seedlings to have more senescent and chlorotic leaves $(P=0.10)$ (Table 2). Although there was no significant difference in the number of green leaves, the average mass of leaves per plant was $12 \%$ higher for the waterlogged plants $(P=0.001)$.

Variations in size and mass between the large and the small seed had no effect on the survival of the seedlings (data not presented). However, there was a close relationship between seed mass and seedling growth. Shoot and root mass of seedlings increased linearly with increasing seed weight. The seed mass was more closely related to the shoot mass $\left(R^{2}\right.$ $\left.=0.50^{* * *}\right)$ than to the root mass $\left(R^{2}=0.21^{* *}\right)$ (Fig. 1). 
Table 2. Effects of main treatment soil water regimes, non-waterlogged control and waterlogged conditions, on various plant parameters in Expt $1(n=200-240)$

\begin{tabular}{lccc}
\hline Parameter & Control & Waterlogged & Significance \\
\hline Survival (\%) & 96.0 & 85.0 & $*$ \\
Shoot mass (g/plant) & 0.080 & 0.095 & $* *$ \\
Root mass (g/plant) & 0.047 & 0.047 & n.s. \\
Total leaves (/plant) & 4.74 & 4.99 & n.s. \\
Green leaves (/plant) & 3.53 & 3.39 & n.s. \\
Senescent leaves (/plant) & 1.20 & 1.59 & n.s. \\
Mean leaf weight (g) & 0.017 & 0.019 & $* * *$ \\
Root: shoot ratio & 0.613 & 0.504 & n.s.
\end{tabular}

* $P<0.05 ; * * P<0.01 ; * * * P<0.001$; n.s., not significant.

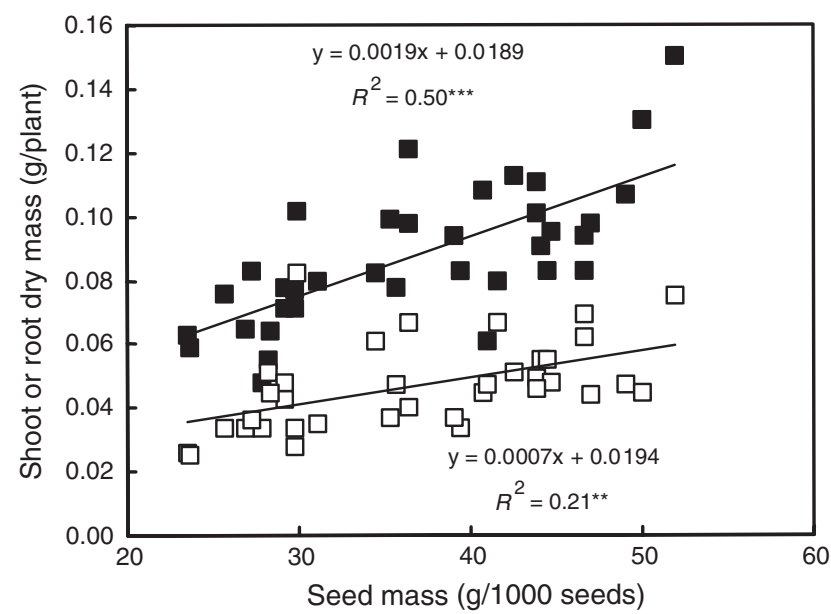

Fig. 1. Relationships between seed mass and shoot ( $\square$ ) and root ( $\square$ ) dry mass across control and waterlogged plants for 18 wheat cultivars in Expt 1 .

\section{Experiment 2}

\section{Oxygen concentrations and chlorosis in waterlogged plants}

The oxygen concentrations, measured after the second and third week of waterlogging, decreased with increasing soil depths from surface water to a depth of $10 \mathrm{~cm}$ or below (Fig. 2). The oxygen concentrations at the end of the second week of waterlogging decreased from $\sim 66 \%$ in the surface water to $\sim 17 \%$ at the $10-\mathrm{cm}$ depth, but there was no apparent chlorosis in the leaves of waterlogged plants. However, after the third week of waterlogging, chlorosis was apparent in the lower leaves of all waterlogged plants, and the oxygen concentrations decreased from $\sim 50 \%$ in the surface water to $<9 \%$ at the $10-\mathrm{cm}$ depth (Fig. 2).

\section{Plant biomass}

During the initial growth and development of cultivars to the 3-leaf stage at Harvest 1, Muir, Brookton, and Tennant were among the largest producers of plant biomass, whereas More, Amery, Silverstar, and Chara were among the smallest producers (Table 3).

There was no significant effect of waterlogging $(P>0.05)$ on plant biomass at Harvest 2. However, a significant

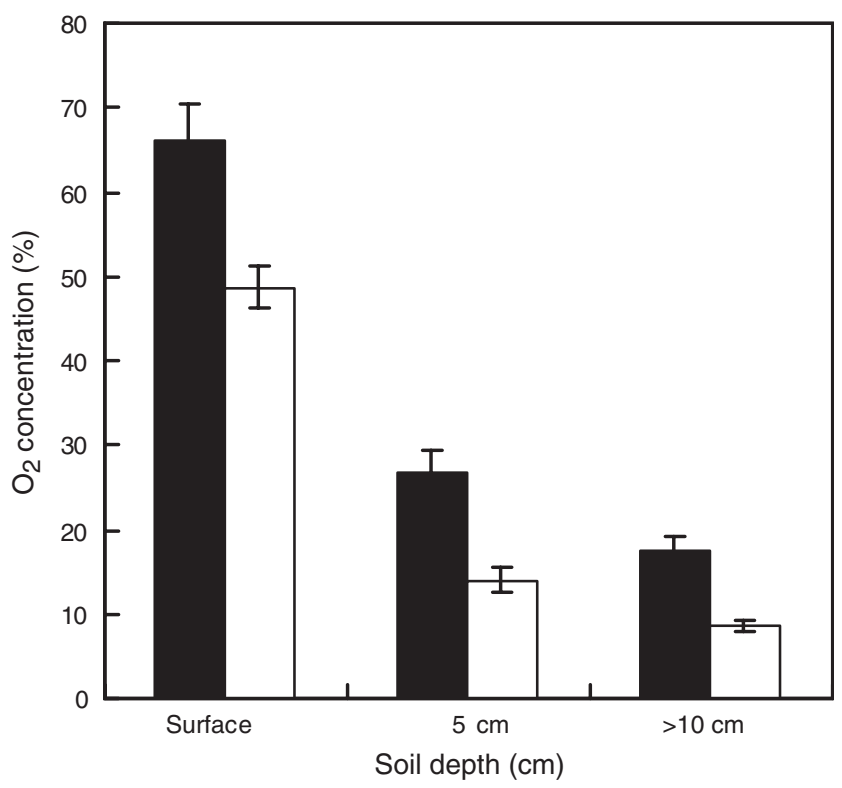

Fig. 2. Oxygen concentrations at various soil depths after 2 ( $\square$ ) and $3(\square)$ weeks of waterlogging in Expt 2. Capped lines are s.e.m.

interaction occurred between the soil water regimes and cultivars $(P<0.01)$. Plant biomass decreased significantly $(P<0.05)$ for Muir, Frame, and Chara, whereas decreases in plant biomass were not significant for other cultivars, when growing conditions changed from control to waterlogged (Table 3). Brookton and Frame were among the largest producers of plant biomass under both control and waterlogged conditions compared with the other wheat cultivars, at Harvest 2 (Table 3).

After the 3-week recovery period from waterlogging, at Harvest 3, there was no effect of soil water regimes (free-draining non-waterlogged control pots $v$. drained waterlogged pots), nor was there any interaction between the soil water regimes and cultivars for plant biomass (Table 3). On average, across the soil water regimes, there were highly significant differences $(P<0.001)$ among the cultivars. Brookton, Frame, and Tennant produced the largest plant biomasses, whereas Amery and Silverstar were the lowest producers of plant biomass at the end of the recovery period, at Harvest 3 (Table 3).

\section{Relative growth rates}

The relative growth rates of various cultivars for plant biomass over time between the 3-leaf stage (Harvest 1) and the 5-leaf stage (Harvest 2) indicated no main effect of soil water regimes, but there was a significant interaction between the soil water regimes and the cultivars (Table 4). The interaction probably resulted from significant decreases in the RGRs for Muir and Chara, not for the other cultivars, when growing conditions changed from control (free-drained) to waterlogged. However, under waterlogged conditions there were no 
Table 3. Effects of main treatment cultivars on plant biomass (g/plant) at Harvest 1, and effects of interaction between soil water regimes and cultivars on plant biomass at Harvest 2 and Harvest 3 in the Expt 2

Values in columns (Harvest 1) and within or across a column (Harvest 2) followed by the same letters are not significantly different $(P>0.05)$

\begin{tabular}{|c|c|c|c|c|c|}
\hline \multirow[t]{2}{*}{ Cultivars } & \multirow{2}{*}{$\begin{array}{c}\text { Harvest } 1 \\
\text { Control }\end{array}$} & \multicolumn{2}{|c|}{ Harvest 2} & \multicolumn{2}{|c|}{ Harvest 3} \\
\hline & & Control & Waterlogged & Control & Recovered \\
\hline \multicolumn{6}{|c|}{ Triticale } \\
\hline Muir & $0.201 \mathrm{e}$ & $0.808 \mathrm{~g}$ & $0.519 f$ & 1.365 & 0.932 \\
\hline \multicolumn{6}{|c|}{ Spring wheat } \\
\hline Brookton & $0.170 \mathrm{de}$ & $0.513 \mathrm{f}$ & $0.444 \mathrm{cdef}$ & 1.056 & 0.743 \\
\hline Frame & $0.134 \mathrm{bcd}$ & $0.502 \mathrm{ef}$ & $0.379 \mathrm{abcd}$ & 0.873 & 0.721 \\
\hline Carnamah & $0.132 \mathrm{bcd}$ & $0.392 \mathrm{bcde}$ & $0.356 \mathrm{abcd}$ & 0.731 & 0.488 \\
\hline Chara & $0.123 \mathrm{abc}$ & $0.455 \mathrm{def}$ & $0.303 \mathrm{ab}$ & 0.708 & 0.652 \\
\hline Silverstar & $0.097 \mathrm{ab}$ & $0.316 \mathrm{ab}$ & $0.263 \mathrm{a}$ & 0.580 & 0.446 \\
\hline Amery & $0.092 \mathrm{ab}$ & $0.346 \mathrm{abcd}$ & $0.278 \mathrm{ab}$ & 0.476 & 0.358 \\
\hline \multicolumn{6}{|c|}{ Winter wheat } \\
\hline Tennant & $0.164 \mathrm{cde}$ & $0.345 \mathrm{abcd}$ & $0.265 \mathrm{a}$ & 1.125 & 0.655 \\
\hline More & $0.084 \mathrm{a}$ & $0.332 \mathrm{abc}$ & $0.276 \mathrm{ab}$ & 0.880 & 0.490 \\
\hline Significance & $* * *$ & \multicolumn{2}{|c|}{$* *$} & \multicolumn{2}{|c|}{ n.s. } \\
\hline 1.s.d. $(P=0.05)$ & 0.0443 & \multicolumn{2}{|c|}{0.1197} & \multicolumn{2}{|c|}{0.2969} \\
\hline
\end{tabular}

${ }^{* *} P<0.01 ; * * * P<0.001 ;$ n.s., not significant.

Table 4. The relative growth rates (RGR-plant biomass) between Harvest 1 and Harvest 2 for various cultivars under control and waterlogged conditions, and degree of waterlogging tolerance (WT) as the percentage ratio of plant biomass and RGR under waterlogged conditions, relative to the non-waterlogged control conditions, in Expt 2

Values within a column and across columns for the RGR (plant biomass) followed by the same letters are not significantly different $(P>0.05)$

\begin{tabular}{|c|c|c|c|c|}
\hline \multirow[t]{2}{*}{ Cultivars } & \multicolumn{2}{|c|}{ RGR-plant biomass } & \multirow{2}{*}{$\begin{array}{c}\text { WT (\% biomass }) \\
(\%)\end{array}$} & \multirow{2}{*}{$\begin{array}{c}\text { WT (\% RGR) } \\
(\%)\end{array}$} \\
\hline & Control & Waterlogged & & \\
\hline \multicolumn{5}{|c|}{ Triticale } \\
\hline Muir & $0.039 \mathrm{f}$ & $0.019 \mathrm{bcde}$ & 64.0 & 50.2 \\
\hline \multicolumn{5}{|c|}{ Spring wheat } \\
\hline Brookton & $0.022 \mathrm{de}$ & $0.016 \mathrm{abcde}$ & 89.0 & 61.9 \\
\hline Frame & $0.023 \mathrm{e}$ & $0.015 \mathrm{abcde}$ & 78.0 & 70.5 \\
\hline Carnamah & $0.020 \mathrm{cde}$ & $0.012 \mathrm{abc}$ & 94.0 & 66.6 \\
\hline Chara & $0.022 \mathrm{de}$ & $0.010 \mathrm{ab}$ & 67.0 & 53.3 \\
\hline Silverstar & $0.013 \mathrm{abcd}$ & $0.011 \mathrm{abc}$ & 112.0 & 136.7 \\
\hline Amery & $0.017 \mathrm{cde}$ & $0.010 \mathrm{ab}$ & 85.0 & 67.3 \\
\hline \multicolumn{5}{|c|}{ Winter wheat } \\
\hline Tennant & $0.011 \mathrm{abc}$ & $0.007 \mathrm{a}$ & 79.0 & 93.1 \\
\hline More & $0.015 \mathrm{abcde}$ & $0.012 \mathrm{abc}$ & 78.0 & 80.9 \\
\hline Significance & \multicolumn{2}{|c|}{ * } & n.s. & n.s. \\
\hline 1.s.d. $(P=0.05)$ & \multicolumn{2}{|c|}{0.0094} & 32.1 & 52.49 \\
\hline
\end{tabular}

$* P<0.05 ;$ n.s., not significant.

significant differences among wheat cultivars for the RGR (Table 4). On average, across the soil water regimes, Brookton and Frame had the highest RGRs, and Silverstar and Tennant had the lowest RGRs among the wheat cultivars (Table 4).
The degree of 'waterlogging tolerance' expressed as the percent ratio of plant biomass and percent ratio of RGR under waterlogged conditions, relative to the control conditions, indicated no significant differences among cultivars (Table 4). 


\section{Seminal and adventitious (nodal) roots}

The seminal root mass decreased from $0.15 \mathrm{~g}$ to $0.07 \mathrm{~g}$ $(P<0.01)$ between the control and waterlogged conditions, at Harvest 2 (Table 5). Muir, Brookton, and Tennant were among the largest $(0.12-0.17 \mathrm{~g})$, whereas Silverstar and Amery were among the smallest $(0.07 \mathrm{~g})$ producers of seminal root mass $(P<0.001)$ (Table 5). There was no

Table 5. Effects of main treatment cultivars on seminal root dry mass (g), and effects of interaction between soil water regimes and cultivars on adventitious root dry mass (g) at Harvest 2, in Expt 2

Values within a column (seminal root mass) and within or across columns (adventitious root mass) followed by the same letters are not significantly different $(P>0.05)$

\begin{tabular}{|c|c|c|c|}
\hline \multirow[t]{2}{*}{ Cultivars } & \multirow{2}{*}{$\begin{array}{l}\text { Seminal root } \\
\text { dry mass }\end{array}$} & \multicolumn{2}{|c|}{ Adventitious root dry mass } \\
\hline & & Control & Waterlogged \\
\hline \multicolumn{4}{|c|}{ Triticale } \\
\hline Muir & $0.175 \mathrm{e}$ & $0.086 f$ & $0.068 \mathrm{ef}$ \\
\hline \multicolumn{4}{|c|}{ Spring wheat } \\
\hline Brookton & $0.143 \mathrm{de}$ & $0.054 \mathrm{cde}$ & $0.057 \mathrm{def}$ \\
\hline Frame & $0.093 \mathrm{abc}$ & $0.035 \mathrm{abcd}$ & 0.043 bcde \\
\hline Carnamah & $0.093 \mathrm{abc}$ & $0.049 \mathrm{cde}$ & $0.050 \mathrm{cde}$ \\
\hline Chara & $0.095 \mathrm{abc}$ & $0.045 \mathrm{bcde}$ & $0.032 \mathrm{abcd}$ \\
\hline Silverstar & $0.071 \mathrm{ab}$ & $0.013 \mathrm{a}$ & $0.040 \mathrm{abcde}$ \\
\hline Amery & $0.068 \mathrm{a}$ & $0.019 \mathrm{ab}$ & $0.025 \mathrm{abc}$ \\
\hline \multicolumn{4}{|c|}{ Winter wheat } \\
\hline Tennant & $0.122 \mathrm{~cd}$ & $0.018 \mathrm{ab}$ & $0.052 \mathrm{cde}$ \\
\hline More & $0.108 \mathrm{bcd}$ & $0.012 \mathrm{a}$ & $0.032 \mathrm{abcd}$ \\
\hline Significance & $* * *$ & \multicolumn{2}{|c|}{ * } \\
\hline 1.s.d. $(P=0.05)$ & 0.0381 & \multicolumn{2}{|c|}{0.0290} \\
\hline
\end{tabular}

$* P<0.05 ; * * * P<0.001$.

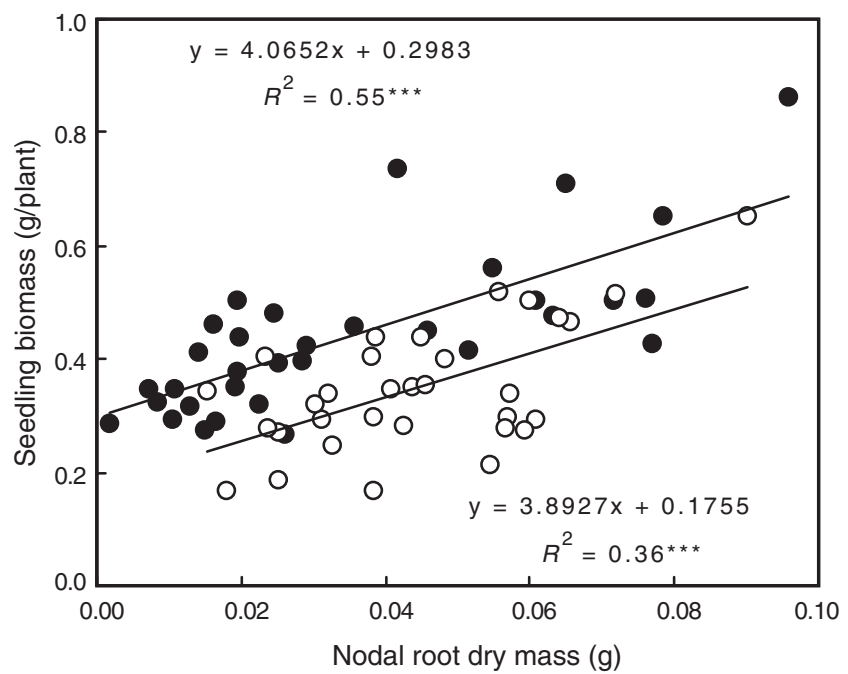

Fig. 3. Linear relationships between adventitious root dry mass and seedling biomass for control $(\bullet)$ and waterlogged $(O)$ plants across 8 wheat and 1 triticale cultivar, at Harvest 2, in Expt 2. interaction between soil water regimes and cultivars for seminal root mass.

The adventitious root mass was not affected by the main treatment soil water regimes; however, there was a significant interaction $(P<0.05)$ between the soil water regimes and cultivars (Table 5 ). This interaction primarily resulted from a significant increase in the adventitious root mass from $0.018 \mathrm{~g}$ to $0.052 \mathrm{~g}$ for Tenant, when the growing conditions changed from control to waterlogged (Table 5). There was no significant change in the adventitious root mass for the other cultivars with changing soil water regimes (Table 5).

There were significant positive linear relationships $(P<0.001)$ between the adventitious root mass and the seedling biomass under both control $\left(R^{2}=0.55^{* * *}\right)$ and waterlogged conditions $\left(R^{2}=0.36^{* * *}\right)$ (Fig. 3). The relationships between seedling biomass and seminal root mass were poor and insignificant (data not shown).

The ratio of adventitious root mass under waterlogged condition to the non-waterlogged control was closely related to the degree of waterlogging tolerance, expressed as the percent ratio of RGR under waterlogging, relative to the RGR under non-waterlogged control conditions (Fig. 4).

\section{Influence of seed mass}

The correlation coefficients between mean seed mass of various wheat cultivars, and plant biomass and adventitious root mass in the Expt 2, indicated close relationships with plant biomass $\left(R^{2}=0.87, P<0.001\right)$, and adventitious root mass $\left(R^{2}=0.77, P<0.001\right)$ in Expt 2 (Fig. 5).

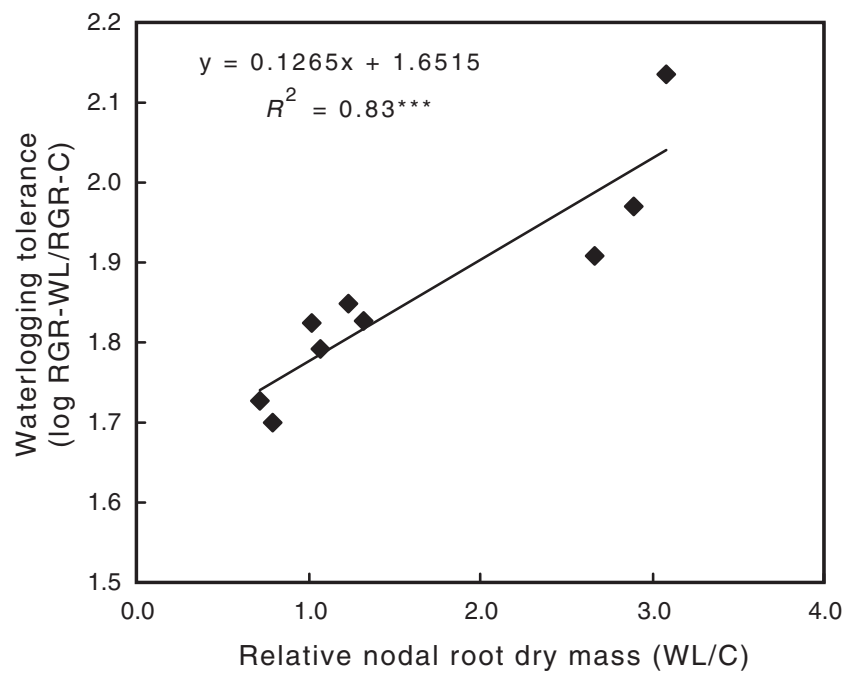

Fig. 4. Relationships between adventitious root dry mass and degree of waterlogging tolerance expressed as the percentage ratio of relative growth rate (RGR) under waterlogged (WL) relative to the non-waterlogged control (C) conditions in Expt 2. Note logarithmic values for the waterlogging tolerance at the $y$-axis. 

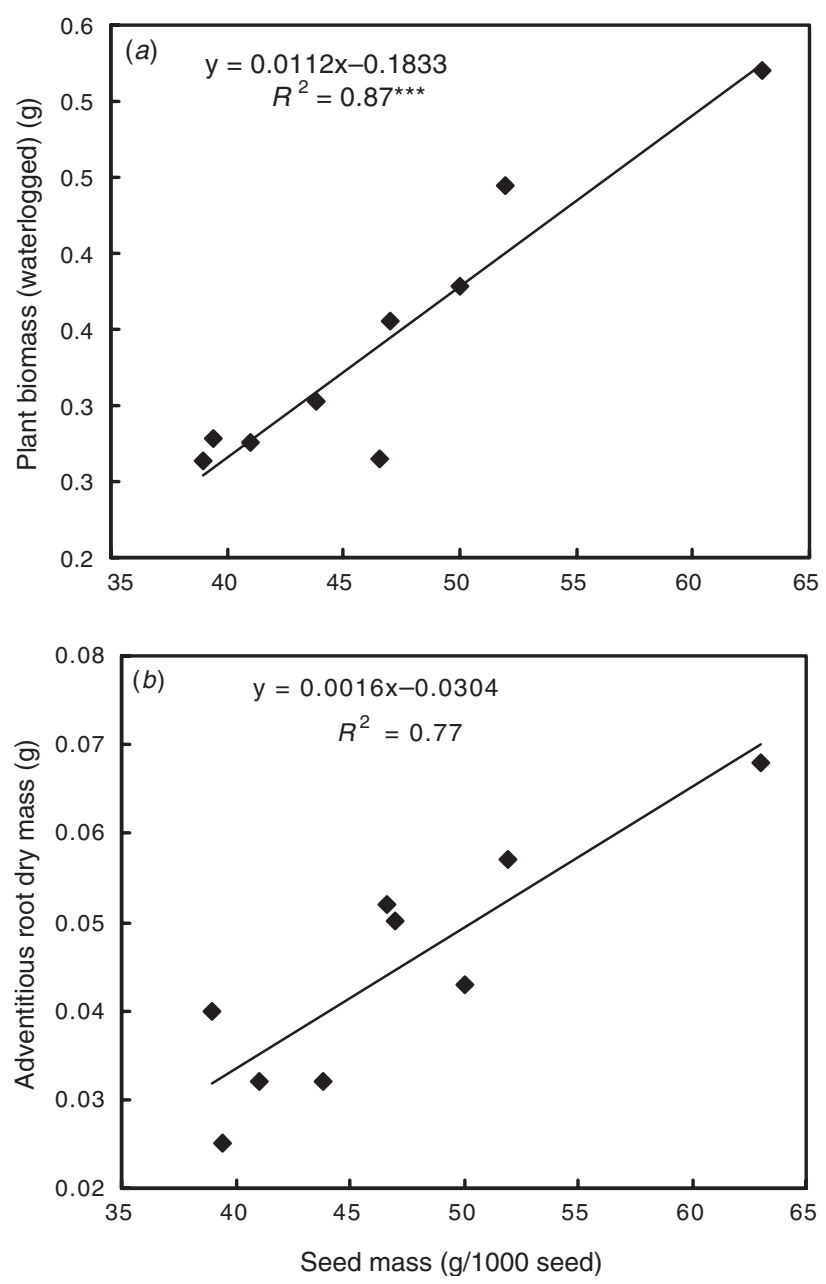

Fig. 5. Relationships between seed mass and (a) plant biomass, and (b) adventitious root dry mass for the waterlogged plants in Expt 2.

\section{Discussion}

Criteria for screening: actual production or degree of waterlogging tolerance?

The results from both experiments indicated that Brookton, followed by Frame, had the largest plant biomass, under both non-waterlogged control and waterlogged conditions, at various growth stages (Tables 1,3). The relative growth rates of these spring wheat cultivars were also better than of the other wheat cultivars, and were similar to a more tolerant species, triticale (cv. Muir) (Table 4). However, the degree of 'waterlogging tolerance' expressed as the percent ratio of biomass or percent ratio of RGR under waterlogged, relative to the control conditions, did not provide any apparent variations among cultivars for their tolerance to waterlogging; rather, least productive cultivars appeared to have the greatest degree of waterlogging tolerance (Table 4). This also indicates that the selection of tolerant cultivars, based on the definition of 'waterlogging tolerance', would be contentious, if the purpose of selection is for commercial use, rather than breeding purposes. For example, the more tolerant species, triticale (cv. Muir), had the lowest degree of 'waterlogging tolerance' in terms of both per cent ratio of biomass and per cent ratio of RGR (Table 4), but had the greatest biomass and RGR, similar to the spring wheat cultivars Brookton and Frame, under waterlogged conditions (Table 3). On the other hand, Silverstar, which was recorded for producing one of the lowest biomass and RGR, appeared to have the greatest degree of 'waterlogging tolerance'. Similar results were also noted in one other study in Western Australia. Setter (2000) reported cv. Spear to be more tolerant than cv. Brookton, based on the definition of 'waterlogging tolerance', although the actual grain yield of Brookton was significantly greater than of Spear under both waterlogged and non-waterlogged conditions in the field at Melijinup, Esperance, WA.

\section{Influence of seed size}

Larger seed undoubtedly produced larger seedlings, compared with the smaller seed, and seed mass was closely related to shoot and root mass in Expt 1 (Table 1, Fig. 1). Variations in plant biomass and development of adventitious roots for the waterlogged plants, in Expt 2, were also highly dependent on seed mass: $87 \%$ and $77 \%$, respectively (Fig. 5). Similar results were reported recently under non-waterlogged conditions for 28 wheat genotypes, assembled from Australian cultivars and overseas germplasms, varying in early vigour (Rebetzke and Richards 1999). In particular, they reported that genotypes with larger seed also had larger leaf areas, which was further related to biomass. Nevertheless, larger seed size and mass are more likely to provide greater carbohydrate reserves for alcoholic fermentation, and would provide greater energy to plants for survival and growth under waterlogged conditions (Setter 2000).

\section{Influence of adventitious roots}

Highly productive cultivars, Muir, Brookton, and Frame, also had the largest mass of adventitious roots, which was closely related to seedling biomass under waterlogged conditions (Table 5, Fig. 3). This is consistent with the findings of Kozlowski (1984), who summarised a generalised correlation between the formation of adventitious roots and productivity for various crops. It is interesting to note that the cultivars with minimum decreases in their actual RGR under waterlogged conditions, relative to their counterparts, the RGR under control conditions, had larger increases in the production of adventitious root dry mass, between non-waterlogged control and waterlogged conditions. For example, Silverstar, Tennant, and More had minimum reductions in their RGRs, and largest increases in the adventitious root mass (Tables 4, 5). This is further supported by a close relationship between the degree of 
'waterlogging tolerance' and ratio of adventitious root mass under waterlogged, relative to the non-waterlogged control, conditions (Fig. 4). This supports further that increased production of adventitious roots was somehow able to maintain the RGRs for these cultivars under waterlogged conditions. In this context, Kozlowski (1984) reported that the formation of adventitious roots was related to stomatal re-opening and an increase of water absorption.

\section{Oxygen concentrations and growing medium for severity of waterlogging}

The oxygen concentration decreased with increasing soil depth and duration of imposed waterlogging (Fig. 2), but the severity of waterlogging on the plant, in terms of visual chlorosis, was only evident when the oxygen concentration dropped to $<10 \%$ in the lower depth after the third week of waterlogging. This is consistent with evidence in the literature that plants mostly suffer with waterlogging when the air-filled porosity in the bulk soil drops to about $15-10 \%$, depending upon the species. In the Expt 2, the detrimental effect of waterlogged conditions was only significant for the Muir, Frame, and Chara (Table 3). Otherwise, on average, across cultivars, there was no significant effect of soil water regimes on plant biomass. This indicates that under the experimental conditions the 3-week waterlogging period and/or reduced oxygen concentration were not enough to severely affect the cultivars. However, the growing medium, sand, could have also resulted in less severity of waterlogging and decreased oxygen concentration on plant growth in this study. For example, Cannell et al. (1984) reported that on a sandy loam soil, more tillers survived waterlogging with no reduction in the grain yield compared with a significant decrease in tiller survival and grain yield on a clay soil.

Similarly, Harberd and Edwards (1982) reported that waterlogging reduced the shoot growth in soil medium, whereas waterlogging in vermiculite medium did not reduce the shoot growth, rather increased the shoot growth under one-third strength nutrient solution, with no difference in root growth between waterlogged and non-waterlogged barley plants. This is consistent with our results from Expt 1, which strongly indicated that under the experimental conditions (1:1 soil:potting mix), waterlogging improved the seedling vigour for the majority of wheat cultivars (Table 2 ). However, it is important to note that the waterlogged plants also formed adventitious roots close to the water surface and there was enough oxygen (30-50\%) in the stored rainwater (used for topping up the water level in the flooded container) in the Expt 1. Formation of adventitious roots, along with an enhanced biochemical activity of alcohol dehydrogenase (ADH) (Kawase 1981; Armstrong 1982), might have contributed to improved growth during waterlogging. In this context, Chan and Burton (1992) reported that an individual plant, which had a 2-fold difference in $\mathrm{ADH}$ activity, also had $25 \%$ more growth during waterlogging. Nevertheless, our results are also consistent with the findings of Trought and Drew (1980a, $1980 \mathrm{~b}$ ), as they reported that shoot dry weight of wheat initially increased above that of the aerobic controls. However, this warrants further investigations.

\section{Acknowledgments}

Findings reported in this study are a part of a larger project, 'Overcoming Root Zone Constraints', funded by the 'Science and Technology Initiative' of the Department of Primary Industries, Victoria. We also extend our thanks to Bradley Kirkwood, Nola McFarlane, Malcolm McCaskil, Kevin F. Smith, and Bob Belford for their cooperation in designing and managing the glasshouse experiments.

\section{References}

Armstrong W (1979) Aeration in higher plants. Advances in Botanical Research 7, 226-232.

Armstrong W (1982) Waterlogged soils. In 'Environment and plant ecology'. 2nd edn (Ed. JR Etherington). pp. 290-330. (Wiley and Sons Ltd: Chichester, UK)

Bacanamwo M, Purcell LC (1999) Soybean root morphological and anatomical traits associated with acclimation to flooding. Crop Science 39, 143-149.

Belford RK (1981) Response of winter wheat to prolonged waterlogging under outdoor conditions. The Journal of Agricultural Science 97, 557-568.

Cannell RQ, Belford RK, Gales K, Dennis CW, Prew RD (1980) Effects of waterlogging at different stages of development on the growth and yield of winter wheat. Journal of the Science of Food and Agriculture 31, 117-132.

Cannell RQ, Belford RK, Gales K, Thompson RJ, Webster CP (1984) Effects of waterlogging and drought on winter wheat and winter barley grown on a clay and a sandy loam soil. I. Crop growth and yield. Plant and Soil 80, 53-66.

Chan JWY, Burton RS (1992) Variation in alcohol dehydrogenase activity and flood tolerance in white clover, Trifolium repens L. Evolution 46, 721-734.

Drew MC (1992) Soil aeration and plant root metabolism. Soil Science 154, 259-268.

Drew MC, Cobb BG, Johnson JR, Andrews D, Morgan PW, Jordan W, He CJ (1994) Metabolic acclimation of root tips to oxygen deficiency. Annals of Botany 74, 281-286. doi:10.1006/ANBO. 1994.1119.

Harberd NP, Edwards KJR (1982) The effect of a mutation causing alcohol dehydrogenase deficiency on flooding tolerance in barley. New Phytologist 90, 631-644.

He CJ, Morgan PW, Drew MC (1996) Transduction of an ethylene signal is required for cell death and lysis in the root cortex of maize during aerenchyma formation induced by hypoxia. Plant Physiology 112, 463-472.

Huang BR, Johnson JW, Box JE, NeSmith DS (1997) Root characteristics and hormone activity of wheat in response to hypoxia and ethylene. Crop Science 37, 812-818.

Huang BR, Johnson JW, Nesmith DS, Bridges DC (1994) Root and shoot growth of wheat genotypes in response to hypoxia and subsequent resumption of aeration. Crop Science 34, 1538-1544.

Justin SHFW, Armstrong W (1987) The anatomical characteristics of roots and plant response and plant response to soil flooding. New Phytologist 106, 465-495. 
Kawase M (1981) Anatomical and morphological adaptation of plants to waterlogging. Horticultural Science 16, 30-34.

Kozlowski TT (1984) 'Flooding and plant growth.' (Academic Press: Orlando, FL)

Lin YH (2000) Studies on cytokinin action in stressed tomato and transgenic white clover plants. PhD thesis. La Trobe University, Melbourne, Australia.

McDonald GK, Gardner WK (1987) Effect of waterlogging on the grain yield response of wheat to sowing date in south-western Victoria. Australian Journal of Experimental Agriculture 27, 661-670.

Meyer WS, Barrs HD (1988) Response of wheat to single short-term waterlogging during and after stem elongation. Australian Journal of Agricultural Research 39, 11-20.

Rebetzke GJ, Richards RA (1999) Genetic improvement of early vigour in wheat. Australian Journal of Agricultural Research 50, 291-301.

Richards RA, Lukacs Z (2002) Seedling vigour in wheat-sources of variation for genetic and agronomic improvement. Australian Journal of Agricultural Research 53,41-50. doi:10.1071/AR00147.
Setter TL (2000) Farming systems for waterlogging prone sandplain soils of the south coast. GRDC Report No. DAW292, Agriculture Western Australia, Perth.

Stephens DJ, Lyons TJ (1998) Rainfall-yield relationships across the Australian wheat belt. Australian Journal of Agricultural Research 49, 211-223.

Trought MCT, Drew MC (1980a) The development of waterlogging damage in young wheat plants in anaerobic solution cultures. Journal of Experimental Botany 31, 1573-1585.

Trought MCT, Drew MC (1980b) The development of waterlogging damage in wheat seedlings (Triticum aestivum L.). 1. Shoot and root growth in relation to changes in the concentrations of dissolved gases and solutes in the soil solution. Plant and Soil 54, 77-94.

Manuscript received 14 October 2002, accepted 12 August 2003 